\title{
Comparative study of titanium elastic nailing versus hip spica in treatment of femoral shaft fractures in children
}

\author{
Dharam Pal Verma*, Rahul Kumar Chandan, R. C. Meena, S. L. Sharma
}

Department of Orthopedics, SMS Medical College and Hospital, Jaipur, Rajasthan, India

Received: 03 June 2016

Revised: 04 June 2016

Accepted: 01 July 2016

*Correspondence:

Dr. Dharam Pal Verma,

E-mail: vermadp1982@gmail.com

Copyright: (c) the author(s), publisher and licensee Medip Academy. This is an open-access article distributed under the terms of the Creative Commons Attribution Non-Commercial License, which permits unrestricted non-commercial use, distribution, and reproduction in any medium, provided the original work is properly cited.

\begin{abstract}
Background: There is no consensus on treatment of closed femoral-shaft fractures in children. We compared hip spica cast with titanium elastic nailing (TEN) in the treatment of femoral-shaft fractures in children.

Methods: Study was conducted at SMS Medical College, Jaipur (Rajasthan). Out of 90 Patients of diaphyseal fracture femur, 45 were treated conservatively by spica cast and 45 were treated with TEN. Follow up done regularly up to twelve months of injury with taking into account, various parameters.

Results: All diaphyseal fractures of femur healed, whether treated conservatively by spica cast or treated operatively with TEN. The time of union and weight bearing was less in operative group as comparative to spica cast group. Ten patients $(22.22 \%)$ in spica group compared to three patients $(6.66 \%)$ in operative group had malunion and two patients $(4.4 \%)$ in spica group compared none in operative group had delayed union.

Conclusions: Results of TEN turned out to be far superior to traction and spica cast treatment in paediatric femoral fractures. Rate of complications was far low with operative than conservative Treatment.
\end{abstract}

Keywords: Spica cast, Titanium elastic nailing, Femoral-shaft fracture, Pediatrics

\section{INTRODUCTION}

Femoral-shaft fractures are among the most common fractures of the lower extremity in children, with an annual incidence of up to 1 per $5,000 .^{1,2}$ There are several different options for treating femoral-shaft fractures in children, including skeletal or skin traction, early or immediate application of a hip spica cast, pontoon spica, closed reduction and minimally invasive plate osteosynthesis, external fixation, plate fixation, and internal fixation with the insertion of intramedullary nails. ${ }^{3,4}$ Selecting the management strategy is dependent on factors such as the presence of other associated injuries or multiple trauma, fracture properties, age, and socioeconomic factors. Because of its clinical effectiveness and low rate of complications, elastic stable intramedullary nailing for fractures of long bones in the skeletally immature patient (e.g. children) has gained widespread popularity. Titanium elastic nailing (TEN) is commonly used to stabilize femoral fractures in schoolaged children, We tried to compare the end results of both modalities of the treatment of diaphyseal fracture femur and found the operative treatment stands far superior to age old traditional cast treatment.

\section{METHODS}

Prospective study was conducted from March 2014 to February 2015. Children with closed femoral shaft fracture, age ranging between 6 to 16 year were included 
in this study. The selection of mode of treatment whether operative or conservative was using random allocation software. Cases with comminuted fracture (Winquist type III and type IV), patients with neuromuscular dystrophy, cerebral palsy, metabolic bone disease, pathological fracture and Anderson Gustilo grade II and III open fractures were excluded from this study.

Every patient included in this study was managed initially skin traction. For patients in TEN operation group the standard technique was applied according to the method described by Flynn and colleagues. ${ }^{5}$ The operations were done in O.T. with full aseptic precautions, under GA/SA on a fracture table. After a linear incision, opening the fascia, and passing the muscle fibres, a hole was opened in the bone and enlarged. Then, each titanium elastic nail was retrograde placed through the distal part of the femur. Each nail was $40 \%$ of the canal diameter at the narrowest site of the femoral shaft. Reduction and fixation was done under $\mathrm{C}$-arm image intensifier. All patients received first generation cephalosporin prophylaxis, which was initiated $12 \mathrm{~h}$ preoperatively and continued 48-72 hours postoperatively. ${ }^{5}$ No supportive plaster slab was given inoperative group. Patients were discharged after 3 days with the advice to attend OPD after 2 week for stitch removal.

Spica cast group was also managed initially with skin traction. Once edema subsided, early one and half spica cast was applied under general anaesthesia. Limb was fixed in spica cast with hip joint at $20^{\circ}$ to $30^{\circ}$ flexion \& knee joint at $10^{\circ}$ to $15^{\circ}$ flexion with $10^{\circ}$ to $15^{\circ}$ external rotation of lower limb. Spica cast was kept for 6 to 8 weeks depending upon the age of patient. After removal of spica cast, non-weight bearing hip, knee and ankle mobilizing exercises were advised for 3 to 4 weeks. After this period protected weight bearing was allowed.

All patients were followed up at 2 week for stitch removal or assessment of spica cast, then at 6 weeks for assessment of union, limb alignment, rotation, range of motion of lower limb joints, operative site. Patients were followed up later every month. Details of hospital stay duration, fracture union time, non-weight bearing time, partial weight bearing time and complications were recorded. Angular and rotational alignment was assessed postoperatively and in subsequent visits by AP and lateral radiographs. Final assessment in both groups was done at six months follow up with Flynn criteria.

Fracture union was defined clinically by ability of painless full weight bearing and radiologically by bridging callus visible at atleast 3 cortices.

Delayed union was defined by persistence of pain \& tenderness, and no visible callus after 3 months of fracture treatment. Non-union was considered by painless movements in 2 planes and absence of visible callus on skiagrams, angular malalignment was defined by more than $10^{\circ}$ angulation in coronal plane and more than $15^{\circ}$ angulation in sagittal plane. According to Wall EJ et al rotation greater than $10^{\circ}$ was defined as rotational malalignament. ${ }^{3}$ Limb length was measured with tape and compared with normal limb to decide limb length discrepancy. Final outcome was assessed using Flynn criteria. ${ }^{4}$

\section{RESULTS}

Initially 100 patients were included in this study with informed consent. 45 patients were treated with early spica cast (within one week) and remaining 45 patients were treated with close reduction and internal fixation with TEN under $\mathrm{C}$-arm control. 5 patients from spica cast group and 5 patients from operative group lost from follow up were excluded from this study.

Remaining 90 patients were followed up properly up to 12 months after the application of spica or TE nailing. In spica cast group 24 were male and 21 were female child. Mean age of this group was 9.6 years. In operative group 30 were male and 15 were female child with mean age of 10.17 years. Follow up period in both groups was 12 months. Average time of bridging callus and union in spica cast group was 4.5 weeks and 10 weeks respectively. In operative group average bridging callus and union time 3.8 weeks and 8.2 weeks respectively. majority of patients $(97 \%)$ in spica group achieved full range of knee movement upto 12 weeks, while in tens group it was $84.4 \%$ cases in 12 weeks. $15.6 \%$ cases in tens group had terminal restriction of knee flexion (20-30 degree) before nail removal but after nail removal complete knee motion occur.

Table 1: Comparision of outcomes between groups.

\begin{tabular}{|lll|}
\hline Parameters & $\begin{array}{l}\text { Spica cast } \\
(\mathbf{n = 4 5})\end{array}$ & TEN $(\mathbf{n = 4 5})$ \\
\hline Age & Mean $=9.6$ & Mean $=10.17$ \\
\hline Male/female & $\begin{array}{l}24(53.3 \%) / \\
21(46.6 \%)\end{array}$ & $\begin{array}{l}30(66.7 \%) / \\
15(33.3 \%)\end{array}$ \\
\hline Hospital stay(days) & $6.68 \pm 2.14$ & $7.46 \pm 2.05$ \\
\hline $\begin{array}{l}\text { Bridging } \\
\text { callus(weeks) }\end{array}$ & Mean $=4.5$ & Mean $=3.8$ \\
\hline Union time(weeks) & Mean $=10$ & Mean $=8.2$ \\
\hline $\begin{array}{l}\text { Weight } \\
\text { bearing(weeks) }\end{array}$ & Mean $=10.2$ & Mean $=8.4$ \\
\hline $\begin{array}{l}\text { Restriction of knee } \\
\text { ROM at 12 weeks }\end{array}$ & $1(2.2 \%)$ & $8(17.7 \%)$ \\
\hline
\end{tabular}

Three patients developed infection and inflammation in operative group and none in spica cast group. Infection was superficial and was cured with oral antibiotics. Pressure sore were found in 4 patients $(8.8 \%)$ of spica cast group at the time of cast removal.

In 2 patients $(4.4 \%)$ of spica cast group delayed union was noted where all patients in operative group got union 
within 3 months time. Ten patients $(22.22 \%)$ in spica cast group got malunion whereas in operative group malunion was noticed only in three $(6.66 \%)$ cases. $1.5 \mathrm{~cm}$ shortening to $1.5 \mathrm{~cm}$ lengthening was noted in 12 patients $(26.66 \%)$ of spica cast group while in operative group 4 patients $(8.88 \%)$ noticed lengthening of $1-1.5 \mathrm{~cm}$. No neurovascular injury was noted in any group.

Table 2: Comparison of complications between groups.

\begin{tabular}{|lll|}
\hline Complication & Spica cast $(\mathbf{n = 4 5})$ & TEN $(\mathbf{n = 4 5})$ \\
\hline $\begin{array}{l}\text { Infection and } \\
\text { inflammation }\end{array}$ & 0 & $5(10 \%)$ \\
\hline Pressure sore & $4(8.8 \%)$ & 0 \\
\hline Delayed union & $2(4.4 \%)$ & 0 \\
\hline Malunion & $10(22.22 \%)$ & $3(6.66 \%)$ \\
\hline $\begin{array}{l}\text { Limb length } \\
\text { discrepancy }\end{array}$ & $12(26.66 \%)$ & $4(8.88 \%)$ \\
\hline
\end{tabular}

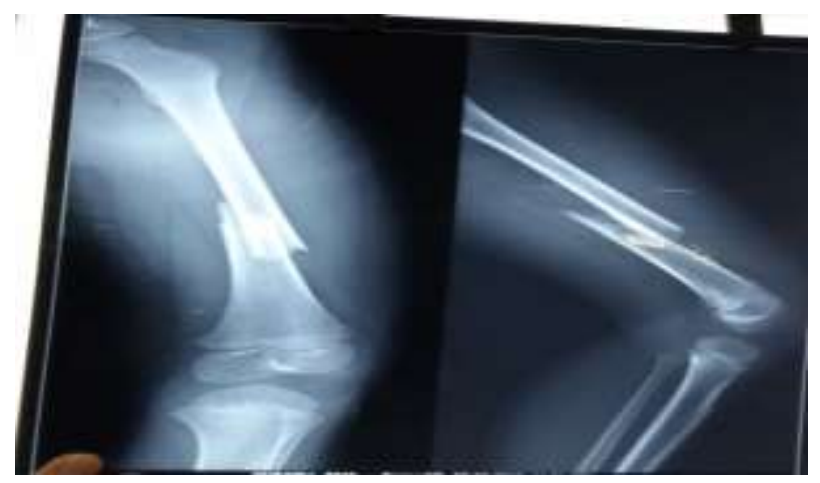

Figure 1: Pre-operative.

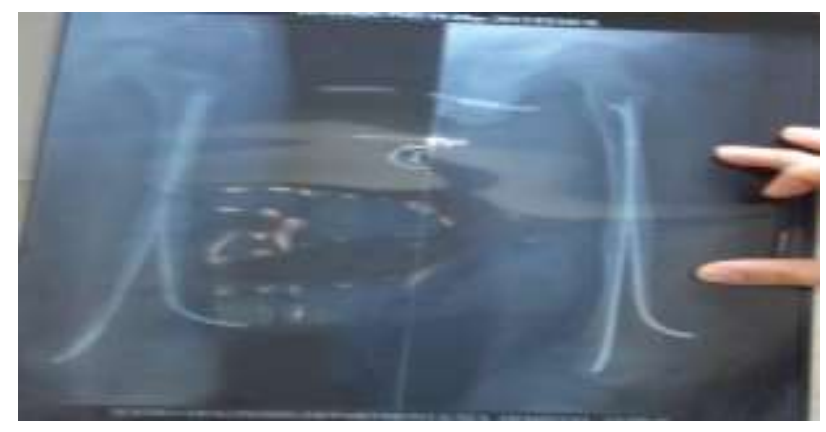

Figure 2: Post-operative at 3 months.

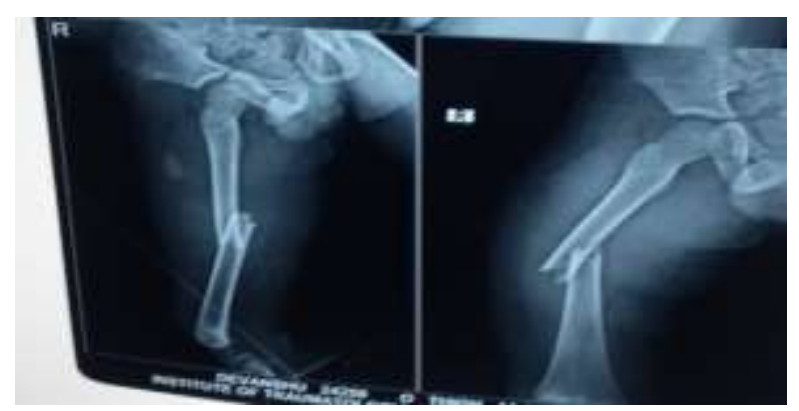

Figure 3: Before spica.

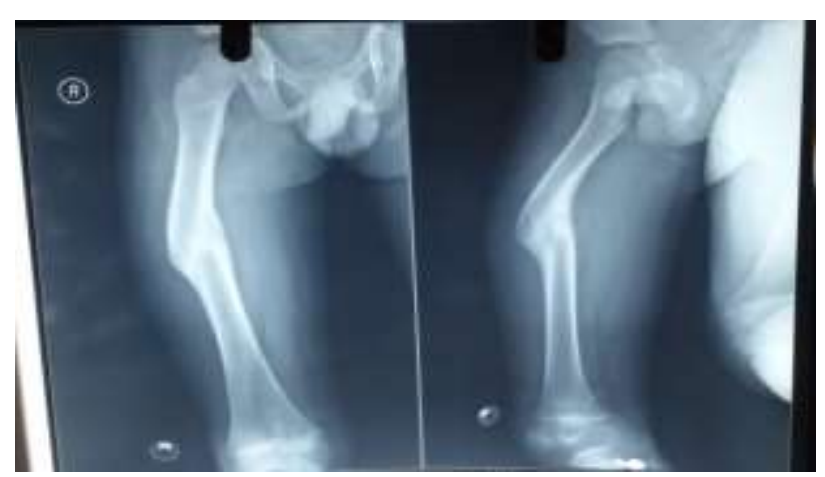

Figure 4: Post spica at 6 months.

\section{DISCUSSION}

Although spica casting with skeletal traction is traditionally used for femoral-shaft fractures in children, recent studies have shown its possible effects on social, economic, educational, and emotional costs. In contrast, elastic intramedullary nailing of femoral-shaft fractures has gained extensive popularity because of its better clinical and psycho-socioeconomic outcomes with lower risk of complications. ${ }^{5-7}$ In our study, we showed the benefits of the TEN surgical method versus traction and spica casting with respect to time of union, time to start walking, limb length discrepancy, complications. Our findings were in agreement with the results of many studies that showed the efficacy and benefits of elastic nails for treating femoral-shaft fractures.

Ligier et al used elastic intramedullary nail (anterograde or retrograde) with Kirschner wires or pins. ${ }^{8}$ They reported more desirable outcomes in 120 femoral-shaft fractures treated with TEN. In Reeve et al study, 41 patients with femoral fractures were treated with traction and casting, and 49 cases underwent intramedullary nailing surgery. ${ }^{9}$ They showed complications were higher in the traction and casting group in comparison with the group undergoing surgery.

In our study, the duration of hospital stay was longer in operative than the traction and spica cast group. This is in contrary with other studies which reported shorter hospital stays with TEN, but is in conformity with Saseendar's study. ${ }^{5,9-12}$ This difference was due to the fact that in our institute plaster room day was earlier than routine ot and long due list of surgery and the spica patients were usually discharged a day or two following spica casting after assessing for the presence of plaster-of Paris related complications.

Our findings showed shorter time of union and weight bearing in the TEN group compared with the spica casting group. It is probably because of better contact of the fracture surfaces and anatomical reduction in patients who underwent TEN surgery. Such earlier recovery milestones have also been shown by Greisberg et $\mathrm{al}^{10}$. and Flynn et al. 
In our study, a higher rate of malunion and limb length discrepancy was observed in the traction and spica group compared with the TEN group. This finding conforms to the results of a similar study conducted by Kirby et al., which compared traction and cast with intramedullary nailing and reported malunion only in the traction and casting group. ${ }^{13}$ In other studies, the rate of malunion in the traction and cast group was higher than that in the TEN group. ${ }^{11,14}$

Flynn score was better in operative group. Common causes of poor Flynn score in spica cast group were malunion and limb length discrepancy. Our study had certain limitations. Treatment cost, time to return school, parents satisfaction were not measured in either group. As with any other new procedure, we had a small sample size, and thus the results could show falsely high complication rates.

\section{CONCLUSION}

In modern era of fashion and comfort, titanium elastic nail treatment stands far better than spica cast for treatment of diaphyseal femoral fractures. TEN takes lesser time for union, has minimal limb length discrepancy and malalignment, allows earlier rehabilitation and return to activities of day to day life than spica cast treatment. Patient feels very much comfortable after TEN treatment as compare to spica treatment. Parents of children, treated with TEN, remained much happier than the other group. Convenience of micturition \& defecation in TEN group, also make it better than spica treatment. Thus TEN treatment proved to be superior than spica cast treatment for diaphyseal femoral fractures.

Funding: No funding sources

Conflict of interest: None declared

Ethical approval: The study was approved by the institutional ethics committee

\section{REFERENCES}

1. Hinton RY, Lincoln A, Crockett MM, Sponseller P, Smith G. Fractures of the femoral shaft in children. Incidence, mechanisms, and sociodemographic risk factors. J Bone Joint Surg Am. 1999;81:500-9.

2. Buess E, Kaelin A. One hundred pediatric femoral fractures: epidemiology, treatment attitudes, and early complications. J Pediatr Orthop B. 1998;7:186-92.

3. Wall EJ, Jain V, Vora V, Mehlman CT, Crawford AH. Complications of titanium and stainless steel elastic nail fixation of pediatric femoral fractures. J Bone Joint Surg Am. 2008;90(6):1305-13.

4. Flynn JM, Hresko T, Reynolds RA, Blasier RD, Davidson R, Kasser J. Titanium elastic nails for pediatric femur fractures: a multicenter study of early results with analysis of complications. J Pediatr Orthop. 2001;21:4-8.

5. Flynn JM, Luedtke LM, Ganley TJ, Dawson J, Davidson RS, Dormans JP, et al. Comparison of titanium elastic nails with traction and a spica cast to treat femoral fractures in children. J Bone Joint Surg Am. 2004;86:770-7.

6. Buechsenschuetz KE, Mehlman CT, Shaw KJ, Crawford AH, Immerman EB. Femoral shaft fractures in children: traction and casting versus elastic stable intramedullary nailing. J Trauma. 2002;53:914-21.

7. Wright JG. The treatment of femoral shaft fractures in children: a systematic overview and critical appraisal of the literature. Can J Surg. 2000;43:1809.

8. Ligier JN, Metaizeau JP, Prevot J. Closed flexible medullary nailing in pediatric traumatology. Chir Pediatr. 1983;24:383-5.

9. Reeves RB, Ballard RI, Hughes JL. Internal fixation versus traction and casting of adolescent femoral shaft fractures. J Pediatr Orthop. 1990;10:592-5.

10. Greisberg J, Bliss MJ, Eberson CP, Solga P, d'Amato C. Social and economic benefits of flexible intramedullary nails in he treatment of pediatric femoral shaft fractures. Orthopedics. 2002;25:106770

11. Herndon WA, Mahnken RF, Yngve DA, Sullivan JA. Management of femoral shaft fractures in the adolescent. J Pediatr Orthop. 1989;9:29-32.

12. Saseendar S, Menon J, Patro DK. Treatment of femoral fractures in children: is titanium elastic nailing an improvement over hip spica casting. J Child Orthop. 2010;4:245-51.

13. Kirby RM, Winquist RA, Hansen ST Jr. Femoral shaft fractures in adolescents: a comparison between traction plus cast treatment and closed intramedullary nailing. J Pediatr Orthop. 1981;1:193-7.

14. Aronson J, Tursky EA. External fixation of femur fractures in children. J Pediatr Orthop. 1992;12:157-63.

Cite this article as: Verma DP, Chandan RK, Meena RC, Sharma SL. Comparative study of titanium elastic nailing versus hip spica in treatment of femoral shaft fractures in children. Int J Res Orthop 2016;2:155-8. 